\title{
Effects of 17 $\alpha$-Methyltestosterone on Growth and Induced Sex Change in Longtooth Grouper Epinephelus bruneus (Bloch)
}

\author{
In-Seok Park ${ }^{1 *}$ and Soo-Yeon Im $^{2}$ \\ ${ }^{1}$ Division of Marine Environment and Bioscience, Korea Maritime University, \\ Busan 606-791, Korea \\ ${ }^{2}$ Mechanical and Environment Research Division, \\ Korea Marine Equipment Reseach Institute, Busan 618-270, Korea
}

\begin{abstract}
We examined the effects of $17 \alpha$-methyltestosterone (MT) on growth and induced sex change in the longtooth grouper Epinephelus bruneus. The growth rate for body weight (GRW) and specific growth rate (SGR) of the group injected with MT over 8 weeks were significantly higher than those of the sham-injected control group, the group injected over 4 weeks, and the control group. Of the orally administrated groups, the GRWs of the control group and the group given $1 \mathrm{~kg}$ of feed with $2.0 \mathrm{mg}$ of MT were highest and did not significantly differ from one another. For SGR, the treatment groups differed significantly, and the SGR of the control group was higher than those of the other groups $(P<0.05)$. The condition factor $(C F)$ of the group injected over 4 weeks was higher than those injected over 8 weeks, the sham-injected control group over 8 weeks, and the control group. The CF did not significantly differ between the sham-injected control group over 8 weeks and the injected group over 8 weeks, but these two groups differed from the control group $(P<0.05)$. The CFs of the groups given $1 \mathrm{~kg}$ of feed with $0.5,1.0$, and $2.0 \mathrm{mg}$ of MT were significantly higher than that of the control group $(P<0.05)$. The feed efficiency ratio was not significantly affected by MT administration. Most of the experimental groups receiving MT developed many unidentified germ cell cysts and perinucleolus oocytes, although neither spermazoa cells nor sex-changed males were observed in any of the treatments.
\end{abstract}

Key words: Longtooth grouper, Epinephelus bruneus, 17 $\alpha$-methyltestosterone, Growth, Induced sex change

\section{Introduction}

Groupers of the genus Epinephelus are widely distributed throughout tropical and subtropical waters worldwide (Yeh et al., 2003b). The longtooth grouper E. bruneus (Bloch) occurs near Jeju Island in Korea, along with the sevenband grouper E. septemfasciatus, red grouper E. akaara, blue spotted grouper E. fario, and black-tipped grouper E. fasciatus (Kim and Lee, 1994). Because of their high growth rate, delicate nature, and market value, these groupers are among some of the most important mariculture species in Korea, Japan, and other Southeast Asian countries (Lee et al., 1996; Park et al., 2008; Park and Park, 2009). However, the expansion of aquaculture for longtooth grouper has been hindered by a lack of

\footnotetext{
*Corresponding author: ispark@hhu.ac.kr
}

stocking seed.

Currently, seed for grouper species were obtained through hormonal treatment of broodstock or by collection of fingerlings from the wild. Obtaining males from the wild for spawning is problematic because groupers are protogynous hermaphrodites (Smith, 1965; Tan and Tan, 1974; Chen et al., 1980; Shapiro, 1987; Bruslé-Sicard et al., 1992; Shapiro et al., 1993; Sadovy and Colin, 1995). Obtaining seed stock can be time-consuming, economically prohibittive, or unfeasible due to the late puberty of females, the extremely long time period required for sex inversion, and the rarity of males in the wild. Therefore, induction of precocious puberty and sex inversion is very important for commercial aquaculture purposes (Sarter et al., 2006).

Mature female broodstock can be readily obtained from captive stock, but simultaneous availability of 
mature male broodstock is the most severe constraint to artificial propagation. However, several research groups have attempted induced spawning in groupers through hormonal manipulation (Chen et al., 1977; Chao and Lim, 1991). In E. tauvina, mature 3-yearold males were obtained when a dose of $145 \mathrm{mg}$ of 17 $\alpha$-methyltestosterone (MT) per kg body weight was given orally, and artificial fertilization was achieved using these sex-changed males (Chen et al., 1977; Chao and Lim, 1991). Extensive efforts have been made to induce sex change by androgen treatment. The effectiveness of sex change induction and the treatment duration required to achieve mature males depend on the type and dose of hormones, as well as the method of hormone administration (Yeh et al., 2003b).

Among synthetic steroids, MT effectively enhances growth in fish. One distinct advantage of anabolic steroids over growth hormones is that they can be provided in food without losing their biological activity. Androgens are mainly produced by the testes and possess anabolic properties for promoting growth of sex-related tissues and of the whole animal. Generally, androgens are more effective than estrogens in promoting growth in fish (Weatherley and Gill, 1987). McBride and Fagerlund (1973) examined the effect of food-administered MT on growth of juvenile coho salmon Oncorhynchus kisutch and chinook salmon $O$. tshawytscha held at $11-15^{\circ} \mathrm{C}$. Coho salmon diets contained $0,1,10$, or 50 mg kg ${ }^{-1}$ of feed containing MT, and chinook salmon diets contained $0,0.2$, or $1 \mathrm{mg} \mathrm{kg}^{-1}$ of MT. All doses were effective in promoting growth in length and weight. Therefore, we investigated the effects of MT on growth and induced sex change relative to the method, dose, and duration of hormonal administration in longtooth grouper.

\section{Materials and Methods}

In April 2009, 1-year-old fish were obtained from the Gyeongsangnam-do Fisheries Resources Research Institute and were transported to and maintained at the Fishery Genetics and Breeding Science Laboratory, Korea Maritime University, Korea. The fish were divided into eight experimental groups: a sham control group injected over 8 weeks (A), a group injected with $17 \alpha$-methyltestosterone (MT; Sigma, St. Louis, MO, USA) over 4 weeks (B), a group injected with MT over 8 weeks (C), a group orally provided $1 \mathrm{~kg}$ of feed with $0.5 \mathrm{mg}$ of MT (E), a group given $1 \mathrm{~kg}$ of feed with $1.0 \mathrm{mg}$ of MT (F), a group given $1 \mathrm{~kg}$ of feed with $2.0 \mathrm{mg}$ of MT (G), and two control groups $(\mathrm{D}, \mathrm{H})$. Each experimental group included 30 fish. Fish were reared for 14 weeks in seawater tanks maintained at $24^{\circ} \mathrm{C}$.

Fish were injected intramuscularly into the tissue behind the first dorsal fin at a dose of 0 (shaminjected control group) or $1 \mathrm{mg}$ MT per $\mathrm{kg}$ of body mass. Injections were prepared from a mixture of coconut butter and $95 \%$ ethanol (Sigma) at a ratio of 1:9 and the total dose of MT. Fish were fed commercial extruded pellets (Aller Aqua Co. Ltd., Aller, Denmark) containing $46.03 \%$ crude protein and $16.58 \%$ crude lipid two times per day, totaling $2 \%$ of the average body weight during the experimental period. MT feed was prepared by spraying $1 \mathrm{~kg}$ of feed with $0.5,1.0$, or $2.0 \mathrm{mg}$ of MT dissolved in 50 $\mathrm{mL}$ of $95 \%$ ethanol (Howerton et al., 1992; Kuwaye et al., 1993). Following evaporation of the ethanol, the feed was stored at $-20^{\circ} \mathrm{C}$. Fish were fed two times daily, totaling $2 \%$ of the average body weight during the experimental period; the experiment was performed with three replicates.

At the start and end of the experiment, fish were weighed to the nearest $0.01 \mathrm{~g}$ using an electronic balance (Acom JW-1, Pocheon, Korea), and their standard length $\left(L_{S}\right)$ was measured to the nearest 0.01 $\mathrm{cm}$ using digital calipers (Mitutoyo CD-20CP, Kawasaki, Japan). Using these data, we estimated the growth rate for body weight (GRW), specific growth rate (SGR), condition factor (CF), and feed efficiency ratio (FER). Differences among groups were analyzed using analysis of variance (ANOVA) in SPSS ver. 9.0 (SPSS Inc., Chicago, IL, USA), and multiple comparisons were performed using Duncan's multiple range test (Duncan, 1955).

For histological analysis, gonads were removed and tissue samples were fixed in $10 \%$ neutral formalin solution $\left(100 \mathrm{~mL}\right.$ formalin, $6.5 \mathrm{~g} \mathrm{Na}_{2} \mathrm{HPO}_{4}$. $\left.12 \mathrm{H}_{2} \mathrm{O}, 4.5 \mathrm{~g} \mathrm{KH}_{2} \mathrm{PO}_{4}, 900 \mathrm{~mL} \mathrm{DW}\right)$ for 5 days. The samples were then re-fixed in Bouin's solution for 24 h. Samples were prepared in 6- $\mu \mathrm{m}$-thick paraffin sections, placed on slides, stained with hematoxylin and eosin-phloxine $\mathrm{B}$, and observed under a microscope (Axioskop; Zeiss, Oberkochen, Germany). Photographs of tissues were also taken.

\section{Results and Discussion}

Several methods of hormone administration for sex inversion in fish have previously been tested, including oral administration, immersion, intramuscular injection, and implantation (Hunter and Donaldson, 1983; Pandian and Sheela, 1995; Beardmore et al., 2001; Piferrer, 2001). Table 1 presents data for 
Table 1. Growth rate for weight (GRW) and specific growth rate (SGR) of the Longtooth grouper Epinephelus bruneus in the 8 experimental groups ${ }^{1}$

\begin{tabular}{|c|c|c|c|c|}
\hline Exp. group ${ }^{2}$ & Initial mass ( $\left.\mathrm{g}_{\text {fish }}{ }^{-1}\right)$ & Final mass $\left(\mathrm{g}\right.$ fish $\left.^{-1}\right)$ & $\mathrm{GRW}^{3}(\%)$ & $\mathrm{SGR}^{4}(\%)$ \\
\hline \multicolumn{5}{|c|}{ Injection group } \\
\hline$A$ & $51.83 \pm 17.279$ & $93.18 \pm 30.113$ & $87.57 \pm 38.578^{\mathrm{ab}}$ & $0.71 \pm 0.172^{b}$ \\
\hline $\mathrm{B}$ & $51.14 \pm 19.783$ & $93.43 \pm 28.930$ & $106.96 \pm 40.556^{\mathrm{bc}}$ & $0.85 \pm 0.109^{c}$ \\
\hline C & $48.19 \pm 13.316$ & $100.26 \pm 29.461$ & $123.01 \pm 29.215^{\mathrm{cz}}$ & $1.00 \pm 0.063^{d}$ \\
\hline D & $54.20 \pm 16.528$ & $83.40 \pm 26.689$ & $61.89 \pm 31.389^{\mathrm{az}}$ & $0.53 \pm 0.132^{a}$ \\
\hline \multicolumn{5}{|c|}{ Orally administrated group } \\
\hline E & $57.76 \pm 19.667$ & $100.36 \pm 32.292$ & $90.22 \pm 39.721^{\mathrm{ab}}$ & $0.79 \pm 0.154^{b}$ \\
\hline $\mathrm{F}$ & $56.45 \pm 15.965$ & $116.93 \pm 41.113$ & $123.88 \pm 41.692^{b}$ & $1.12 \pm 0.143^{c}$ \\
\hline $\mathrm{G}$ & $58.44 \pm 13.474$ & $111.76 \pm 44.353$ & $96.87 \pm 46.368^{\text {ba }}$ & $0.91 \pm 0.308^{b}$ \\
\hline $\mathrm{H}$ & $63.03 \pm 17.956$ & $93.39 \pm 33.913$ & $55.09 \pm 24.922^{\mathrm{ab}}$ & $0.55 \pm 0.151^{a}$ \\
\hline
\end{tabular}

${ }^{1}$ The differences among groups were analyzed by ANOVA using the SPSS statistics package, and multiple comparisons were performed using Duncan's multiple range test. Each value is mean \pm standard error $(n=30)$ of triplicate experiments. Values in the same column sharing a common superscript are not significantly different $(P<0.05)$.

${ }^{2} \mathrm{~A}$; sham-injected control group over 8 weeks, $\mathrm{B}$; the group injected over 4 weeks, $\mathrm{C}$; the group injected over 8 weeks, E; the group given $1 \mathrm{~kg}$ of feed with $0.5 \mathrm{mg}$ of MT, F; the group given $1 \mathrm{~kg}$ of feed with $1.0 \mathrm{mg}$ of MT, $\mathrm{G}$; the group given $1 \mathrm{~kg}$ of feed with $2.0 \mathrm{mg}$ of MT and D, H; control group.

${ }^{3} \mathrm{GRW}(\%)=$ (final mean body mass-initial mean body mass $) \times 100$ initial mean body mass ${ }^{-1}$.

${ }^{4}$ SGR $(\%)=\left(\right.$ final mean body mass-initial mean body mass) rearing day ${ }^{-1}$.

GRW and SGR of longtooth grouper in the various experimental groups. Survival rate in all experimental groups was $100 \%$ and was not affected by the MT treatments.

GRW and SGR of the group injected over 8 weeks (C) were significantly higher than those of the shaminjected control group over 8 weeks (A), the group injected over 4 weeks (B), and control group (D) $(P<0.05$; Table 1$)$. In fish orally provided MT, the GRW of the group provided $1 \mathrm{~kg}$ of feed with $1.0 \mathrm{mg}$ of MT (F) was the highest among the examined groups. SGR of the $\mathrm{F}$ group was also significantly higher than those of the other groups $(P<0.05$; Table $1)$.

Data for the CF and FER of the longtooth grouper are provided in Table 2. CF of the group injected over 4 weeks (B) was higher than those of A, C, and D groups. FER of groups $\mathrm{A}, \mathrm{B}$, and $\mathrm{C}$ did not significantly differ from one another, but they did differ from the control group $\mathrm{D}(P<0.05)$. CFs of the groups given $1 \mathrm{~kg}$ of feed with MT (E, F, and G) were significantly higher than that of the control group $(\mathrm{H})$. The experimental groups significantly differed in FER. FER of group $\mathrm{F}$ was significantly higher than those of the other groups $(P<0.05$; Table 2$)$.

MT affected the growth of individuals that were given the hormone compared to those receiving no hormone. MT significantly enhances the growth rates of goldfish Carassius auratus, juvenile coho salmon, and chinook salmon (Hirose and Hibiya, 1968; McBride and Fagerlund, 1973). Similarly, MT treat-
Table 2. Condition factor (CF), feed efficiency ratio (FER) of the longtooth grouper Epinephelus bruneus ${ }^{1}$

\begin{tabular}{ccc}
\hline Exp. group $^{2}$ & $\mathrm{CF}^{3}$ & FER $^{4}$ \\
\hline Injection group & & \\
A & $1.60 \pm 0.142^{\mathrm{ab}}$ & 0.03 \\
B & $1.67 \pm 0.214^{\mathrm{b}}$ & 0.04 \\
C & $1.58 \pm 0.145^{\mathrm{ab}}$ & 0.04 \\
D & $1.51 \pm 0.064^{\mathrm{a}}$ & 0.02 \\
Orally administrated group & & \\
E & $1.65 \pm 0.102^{\mathrm{b}}$ & 0.02 \\
F & $1.61 \pm 0.085^{\mathrm{b}}$ & 0.03 \\
G & $1.61 \pm 0.314^{\mathrm{b}}$ & 0.02 \\
H & $1.45 \pm 0.115^{\mathrm{a}}$ & 0.02 \\
\hline
\end{tabular}

${ }^{1}$ The differences among groups were analyzed by ANOVA using the SPSS statistics package, and multiple comparisons were performed using Duncan's multiple range test. Each value is mean \pm standard error $(n=30)$ of triplicate experiments. Values in the same column sharing a common superscript are not significantly different $(P<0.05)$.

${ }^{2} \mathrm{~A}$; sham-injected control group over 8 weeks, B; the group injected over 4 weeks, $\mathrm{C}$; the group injected over 8 weeks, $\mathrm{E}$; the group given $1 \mathrm{~kg}$ of feed with $0.5 \mathrm{mg}$ of MT, F; the group given $1 \mathrm{~kg}$ of feed with $1.0 \mathrm{mg}$ of MT, G; the group given $1 \mathrm{~kg}$ of feed with $2.0 \mathrm{mg}$ of MT and $\mathrm{D}, \mathrm{H}$; control group. ${ }^{3} \mathrm{CF}=$ body mass $\left.\times 100\{\text { (total length })^{3}\right\}^{-1}$.

${ }^{4} \mathrm{FER}=$ mass gain of fish feed consumed ${ }^{-1}$.

ment increased the growth rate of longtooth grouper in our study. Therefore, we were able to determine not only the effect of MT treatment on fish growth, 

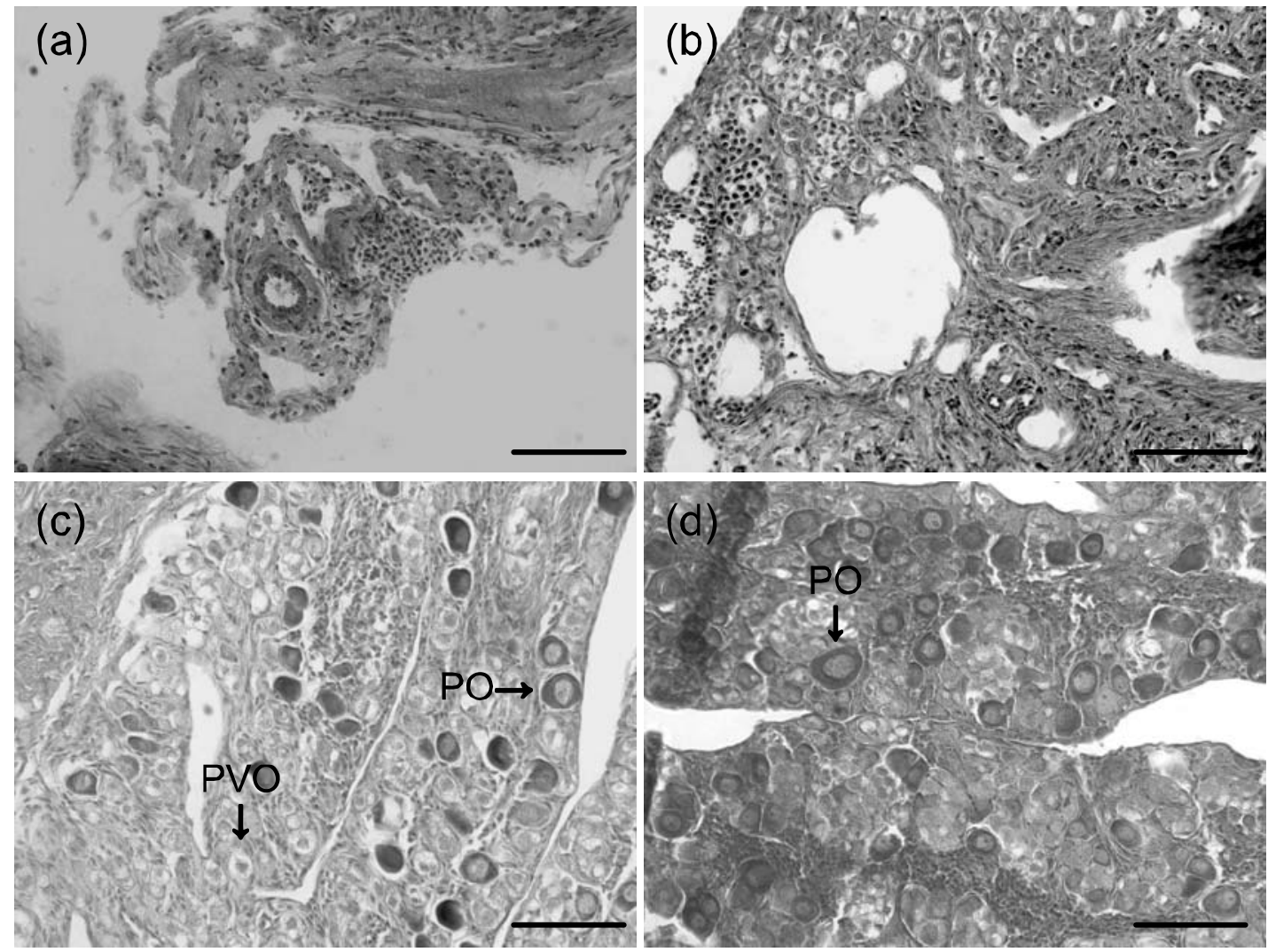

Fig. 1. Gonadal histology of the longtooth grouper Epinephelus bruneus during the experimental period. a Ovary from fish prior to treatment, b ovaries from groups A, D and $\mathrm{H}$ group, $\mathrm{c}$ and $\mathrm{d}$ ovaries from groups $\mathrm{B}, \mathrm{C}$, $\mathrm{E}, \mathrm{F}$ and $\mathrm{G}$ group. The bars are $100 \mu \mathrm{m}$. PO, primary oocyte; PVO, pre-vitellogenic oocyte.

but also a more effective dose of MT treatment. However, we were unable to determine the most effective dose, duration, or method of MT administration for longtooth grouper.

Gonadal histology of each group is illustrated in Fig. 1. Initially, fish exhibited mostly unidentified germ cell cysts (Fig. 1a). All fish in groups A, D, and $\mathrm{H}$ had unidentified germ cell cysts (Fig. 1b). In addition, fish in groups B, C, E, F, and G had previtellogenic and primary oocytes in the ovaries (Fig. 1c, d). No spermazoa were present in the fish of any group. We did not obtain induced sex-changed males.

Sex change in longtooth grouper induced by androgen administration is essential for accelerating the reproductive cycle and for larval rearing. Yeh et al. (2003a) obtained $66.7 \%$ sex-changed males after a 70 day implantation in E. tukula, which was lower than rates for E. fario and E. salmonoides (87-100\%; Yeh et al., 1988), E. tauvina ( $>85 \%$; Chao and Lim, 1991), and E. suillus (>85\%; Tan-Fermin et al., 1994). In contrast, we did not obtain sex-changed males, perhaps due to species differences, the timing of the experiment, initial fish size, or the dose and manner of hormone administration. Thus, further studies are necessary to elucidate the effective dose, duration, and method of MT administration for longtooth grouper.

\section{Acknowledgments}

This research was funded through project 20100021293 of the National Research Foundation of Korea. Comments from anonymous reviewers greatly improved the quality of this manuscript. We declare that all experiments in this study complied with the current laws of Korea.

\section{References}

Beardmore JA, Mair GC and Lewis RI. 2001. Monosex male production in finfish as exemplified by tilapia: applications, problems, and prospects. Aquaculture 197, 283-301.

Bruslé-Sicard S, Debas L, Fourcault B and Fuchs J. 1992. 
Ultrastructural study of sex inversion in a protogynous hermaphrodite, Epinephelus microdon (Teleostei, Serranidae). Reprod Nutr Dev 32, 393-406.

Chao TM and Lim LC. 1991. Recent developments in the breeding of grouper (Epinephelus spp) in Singapore. Singapore J Primary Ind 19, 78-93.

Chen CP, Hsieh HL and Chang KH. 1980. Some aspects of the sex change and reproductive biology of the grouper, Epinephelus diacanthus (Cuvier et Valenciensis). Bull Inst Bot Acad Sin 19, 11-17.

Chen FY, Chow M, Chao TM and Lim R. 1977. Artificial spawning and larval rearing of the grouper, Epinephelus twain (FORSKAL) in Singapore. Singapore J Primary Ind 5, 1-21.

Duncan DB. 1955. Multiple-range and multiple $F$ tests. Biometrics 1, 1-42.

Hirose K and Hibiya T. 1968. Physiological studies on growth-promoting effect of protein-anabolic steroids on fish. I. Effects on goldfish. Bull Jap Soc Sci Fish 34, 466-472.

Howerton RD, Okimoto DK and Grau EG. 1992. The effect of orally aiministered $17 \alpha$-methyltestosterone and triiodothyronine on growth and proximate body composition of seawater-adapted tilapia (Oreochromis mossambicus). Aquacult Fish Manage 23, 123-128.

Hunter G and Donaldson EM. 1983. Hormonal sex control and its application to fish culture. In: Hoar WS, Randall DJ, Donaldson EM (eds) Fish Physiology. Academic Press, Orlando, Florida, 223-303.

Kim IS and Lee WO. 1994. Fish fauna from Cheju Island, Korea. The Study Group of Korean Fish Fauna Department of Biology, Chonbuk National University, $1-51$.

Kuwaye TT, Oimoto DK, Shimoda SK, Howerton RD, Lm H-R, Pang PKT and Grau EG. 1993. Effect of $17 \alpha-$ methyltestosterone on the growth of the euryhaline tilapia, Oreochromis mossambicus, in fresh water and in seawater. Aquaculture 113, 137-152.

Lee Y-D, Kim H-B, Song C-B, Rho S and Lee J-J. 1996. Hormonal induction of sex reversal in serranid fish, Epinephelus septemfasciatus. J Aquaculture 9, 19-23.

McBride JR and Fagerlund UHM. 1973. The use of $17 \alpha-$ methyltestosterone for promoting weight increases in juvenile pacific salmon. J Fish Res Board Can 30, 1099-1104.

Pandian TJ and Sheela SG. 1995. Hormonal induction of sex reversal in fish. Aquaculture 138, 1-22.

Park MO and Park I-S. 2009. Long-term effects of passive integrated transponder (PIT) tagging on the kelp grouper Epinephelus bruneus. J Fish Biol 74, 285-288.

Park MO, Hur WJ, Im S-Y, Seol D-W, Lee JW and Park
I-S. 2008. Anesthetic efficacy and physiological responses to clove oil-anaesthetized kelp grouper Epinephelus bruneus. Aquacult Res 39, 877-884.

Piferrer F. 2001. Endocrine sex control strategies for the ferminization of teleost fish. Aquaculture 197, 229281.

Sadovy Y and Colin PL. 1995. Sexual development and sexuality in the Nassau grouper. J Fish Biol 46, 961976.

Sarter K, Papadaki M, Zanuy S and Mylonas CC. 2006. Permanent sex inversion in 1-year-old juveniles of the protogynous dusky grouper (Epinephelus marginatus) using controlled-release $17 \alpha$-methyltestosterone implants. Aquaculture 256, 443-456.

Shapiro DY. 1987. Differentiation and evolution of sex change in fishes. Bioscience 37, 490-496.

Shapiro DY, Sadovy Y and McGehee MA. 1993. Periodicity of sex change and reproduction in the rod hind, Epinephelus guttatus, a protogynous grouper. Bull Mar Sci 53, 1151-1162.

Smith CL. 1965. The patterns of sexuality and the classification of serranid fishes. American Museum Novitates 2207, 1-20.

Tan SM and Tan KS. 1974. Biology of the tropical grouper, Epinephelus tauvina (Forskal). I: A preliminary study on hermaphroditism in E. tauvina. Singap. J Primary Ind 2, 123-133.

Tan-Fermin JD, Garcia LMB and Castillo AR Jr. 1994. Induction of sex inversion on juvenile grouper, Epinephelus suillus, (Valenciennes) by injections $17 \alpha-$ methyltestosterone. Jap J Ichthyol 40, 413-420.

Yeh S-L, Dai Q-C, Chu Y-T, Kuo C-M, Ting Y-Y and Chang C-F. 2003a. Induced sex changed, spawning and larviculture of potato grouper, Epinephelus tukula. Aquaculture 228, 371-381.

Yeh S-L, Kuo C-M, Thing Y-Y and Chang C-F. 2003 b. Androgens stimulate sex change in protogynous grouper, Epinephelus coiodes: spawning performance in sex-changed males. Comp Biochem Physiol C 135, 375-382.

Yeh S-L, Thing Y-Y and Kuo C-M. 1988. Induced sex reversal of grouper (Epinephelus salmonoides, Epinephelus fario) after implantation of pelleted androgen. Bull Taiwan Fish Res Inst 45, 103-114.

Weatherley AH and Gill HS. 1987. The biology of fish growth. In: Weatherley AH, Gill HS (eds) Influence of Hormones. Academic Press, Orlando, Florida, 177208.

(Received 10 August 2010; Revised 3 March 2011; Accepted 14 March 2011) 